Article available at http://WwW.parasite-journal.org or nttp://dx.dol.org/10.1051/parasite/199704429g

\title{
Eighty-year research of Phlebotomine sandflies (Diptera: Psychodidae) in China (1915-1995). II. Phlebotomine vectors of leishmaniasis in China
}

\author{
ZHANG L.M. \& LENG Y.J.*
}

\section{Summary :}

The human leishmaniasis vector - phlebotomine sandfly - was proven in China, i.e. P. alexandri, P. chinensis, P. longiductus, $P$. sichuanensis and $P$. smirnovi. The infectious rate, biology and distribution of these vectors are shown in this review. Two disputed questions about $P$. chinensis and $P$. sichuanensis, $P$. smirnovi and $P$. wui are discussed. At last, the vectors of animal leishmania are provided, i.e. the vectors of great gerbil leishmania: $P$. alexandri, $P$. andrejievi, $P$. caucasicus, $P$. mongolensis and $P$. smirnovi, and the vector of lizards leishmania: S. sinkiangensis.

KEY WORDS : phlebotomine sandflies, vectors, leishmaniasis, China
Résumé : QuATRE-VINGT ANS DE RECHERCHE SUR LES PHLÉBOTOMES (Diptera : Psychodidae) EN Chine (1915-1995). II. Les PHLÉBotomes vecteurs de leishmaniose en Chine

Les phlébotomes dont on a démontré qu'ils sont vecteurs de la leishmaniose en Chine sont P. alexandri, P. chinensis,

$P$. longiductus, $P$. sichuanensis et $P$. smirnovi. Les taux de contamination, la biologie et la distribution géographique de ces vecteurs sont précisés. Deux controverses concernant $P$. chinensis et $P$. sichuanensis d'une part, $P$. smirnovi et $P$. wui d'autre part, sont abordées. Enfin, les vecteurs de la leishmaniose animale sont répertoriés: $P$. alexandri, $P$. andrejievi, $P$. caucasicus, $P$. mongolensis et $P$. smirnovi pour la grande gerbille, S. sinkiangensis pour le lézard.

MOTS CLÉS : phlébotome, vecteur, leishmaniose, Chine.
The presence of visceral leishmaniasis (VL) in China was first confirmed after an autopsy of a German soldier in 1909. VL used to be one of the most serious parasitic diseases in China. The vector, phlebotomine sandfly, was proven in China as early as in the twenties. In this paper, a brief review of phlebotomine vectors in China is given.

\section{HUMAN LEISHMANIASIS VECTORS}

\section{THE VECTOR SPECIES IN CHINA}

1 n China, five species of phlebotomine sandflies are incriminated to be the vectors of VL, i.e. Phlebotomus (A.) chinensis, P. (A.) longiductus, $P$. (A.) sichuanensis, $P$. (P.) alexandri and $P$. (L.) smirnovi (Leng, 1988a).

\footnotetext{
* Department of Medical Parasitology, Faculty of Medicine, Jinan University, Guangzhou, 510632, China PR.

Correspondence: Y.J. Leng.

Tel: 86-20-8551-6511 ext 4653/4629

e-mail: oyxy@maina.jnu.edu.cn.
}

$P$. chinensis was proven a vector of VL in the early twenties according to epidemiological study, coincidential distribution with VL, artificial infection, presence of natural infection and successful experimental transmission. After the fifties, four more flies were incriminated as vectors/suspected vectors (Tables I, II). After having been fed on cotton rats or hamsters infected with Leishmania donovani, 85.1 to $93.3 \%$ of $P$. alexandri were infected, the promastigotes not only developing in the stomach but also invading the pharynx, buccal cavity and proboscis (Guan, 1986a, b). The natural infection of $P$. alexandri is about $2.0 \%$. In addition, golden hamsters could also experimentally be infected by the bite of $P$. alexandri infected with promastigotes of L. donovani (Guan et al., 1986b).

P. smirnovi: during the sandfly season, the natural infection rate of promastigotes was $5.7 \%$, and experimental infection rate is about 35.3 to $85.1 \%$ after feeding, in which case the promastigotes invade into the pharynx (Xiong et al., 1974; Wang, 1983; Guan et al., 1986a, 1992, 1994a). The experimental infection rate of P. longiductus and P. sichuanensis is 54.2 to $62.2 \%$ and $60.8 \%$ respectively (Xiong et al., 1974; Yin, 1985; Wang, 1983; Guan, 1986a). 
Distribution of promastigotes in sandflies

\begin{tabular}{|c|c|c|c|c|c|c|c|c|c|}
\hline Species* & Infected rate $(\%)$ & Proboscis & Buccal cavity & Pharynx & CEsophagus & Pro-gut & Mid-gut & Hind-gut & Reference \\
\hline P. al & 48.9 & 1.5 & - & 10.6 & 30.3 & 63.6 & 100.0 & 12.1 & Xiong, 1963 \\
\hline P. al & 85.1 & 2.5 & 2.5 & 2.0 & 85.0 & 100.0 & 100.0 & 5.0 & Guan, $1986 a$ \\
\hline P. al & 93.3 & 5.2 & 1.3 & 29.1 & 78.9 & 99.6 & 100.0 & 5.7 & Guan, $1986 b$ \\
\hline P. ch & 69.2 & 2.2 & - & 17.5 & 45.4 & 84.3 & 100.0 & 19.7 & Xiong, 1988 \\
\hline P. ch & 65.0 & 3.4 & - & 27.1 & 53.6 & 85.4 & 100.0 & 19.3 & Xiong, 1992 \\
\hline P. lo & 54.2 & - & - & 8.7 & 70.2 & 88.1 & 97.7 & 20.2 & Xiong, 1974 \\
\hline P. lo & 62.2 & 7.1 & 0 & 25.0 & 75.0 & 100.0 & 100.0 & 3.6 & Guan, $1986 a$ \\
\hline P. si & 60.8 & - & - & 6.7 & 48.9 & 55.6 & 100.0 & 8.9 & Yin, 1985 \\
\hline P. sm & 85.1 & - & - & 6.6 & 35.0 & 64.9 & 100.0 & 39.3 & Xiong, 1974 \\
\hline P. sm & 35.3 & - & - & 33.3 & 83.3 & 100.0 & 100.0 & 33.3 & Guan, $1986 a$ \\
\hline
\end{tabular}

${ }^{*}$ P. al: P. alexandri; P. ch: P. chinensis; P. lo: P. longiductus; P. si: P. sichuanensis; P. sm: P. smirnovi.

Table I. - Artificial infection of five vectors with $L$. donovani.

Distribution of promastigotes in sandflies

\begin{tabular}{|c|c|c|c|c|c|c|c|c|c|}
\hline \multirow[b]{2}{*}{ Species* } & \multirow[b]{2}{*}{ Infected rate $(\%)$} & & \multirow[b]{2}{*}{ Reference } \\
\hline & & Proboscis & Buccal cavity & Pharynx & Esophagus & Pro-gut & Mid-gut & Hind-gut & \\
\hline P. al & 2.0 & 7.7 & 7.7 & 46.2 & 61.5 & 92.3 & 100.0 & - & Guan, $1986 b$ \\
\hline P. ch & 0.23 & - & - & +++ & +++ & ++++ & ++++ & - & Xiong, 1988 \\
\hline P. ch & 0.31 & ++ & - & +++ & +++ & ++++ & ++++ & - & Xiong, 1992 \\
\hline P. $\mathrm{sm}$ & 5.7 & - & - & 23.5 & 70.6 & 88.2 & 94.1 & 29.4 & Xiong, 1974 \\
\hline
\end{tabular}

* See table I.

Table II. - Natural infection of vectors with L. donovani.

\section{BIOLOGY AND DISTRIBUTION OF VECTORS}

The vectors could be grouped into two categories: endophilic ( $P$. alexandri, $P$. chinensis and $P$. longiductus) and exophilic vectors (P. sichuanensis and $P$. smirnovi). Their zoogeographical distribution are showed in figure 1.

$P$. chinensis, one of the three endophilic vectors, was the main and most important vector widely distributed over Northeast, North, East and eastern part of Northwest China. It is an anthropophilic and a predominant species in the old VL epidemic areas. The other two endophilic vectors are: $P$. longiductus distributed in old residential quarters of western Xinjiang; $P$. alexandri distributed in western Xinjiang, western Inner Mongolia and western Gansu as high as 3,200 m altitude, Qilianshan Mt. (Leng \& Zhang, 1993). The experimental results indicate that $P$. alexandri is also an anthropophilic species of epidemiological significance in the transmission of VL in the studied area (Guan et al., 1986b).
P. sichuanensis is found to be an exophilic vector in the mountainous region of northwestern Sichuan, southern Gansu, Qinghai and Tibet (above 1,000 $\mathrm{m}$ altitude). P. smirnovi is another exophilic vector in the desert and savannah area of Xinjiang, western Inner Mongolia and Gansu. These two species prefer sucking blood of wild animals, and also bite man. They have an important role in transmission of zoonotic leishmaniasis. Studies indicate that sandflies of the different species act as vectors of VL transmission in different regions.

\section{SEVERAL OBJECTS IN Disputation}

\section{1/ P. chinensis and P. sichuanensis \\ (Leng \& Zhang, 1992)}

$P$. sichuanensis is considered by some authors as a large type of $P$. chinensis. The authors carried out a series of comparative studies of these two flies according to the following facts, and proved that P. sichuanensis is a separate species instead of a "large type of $P$. chinensis". 

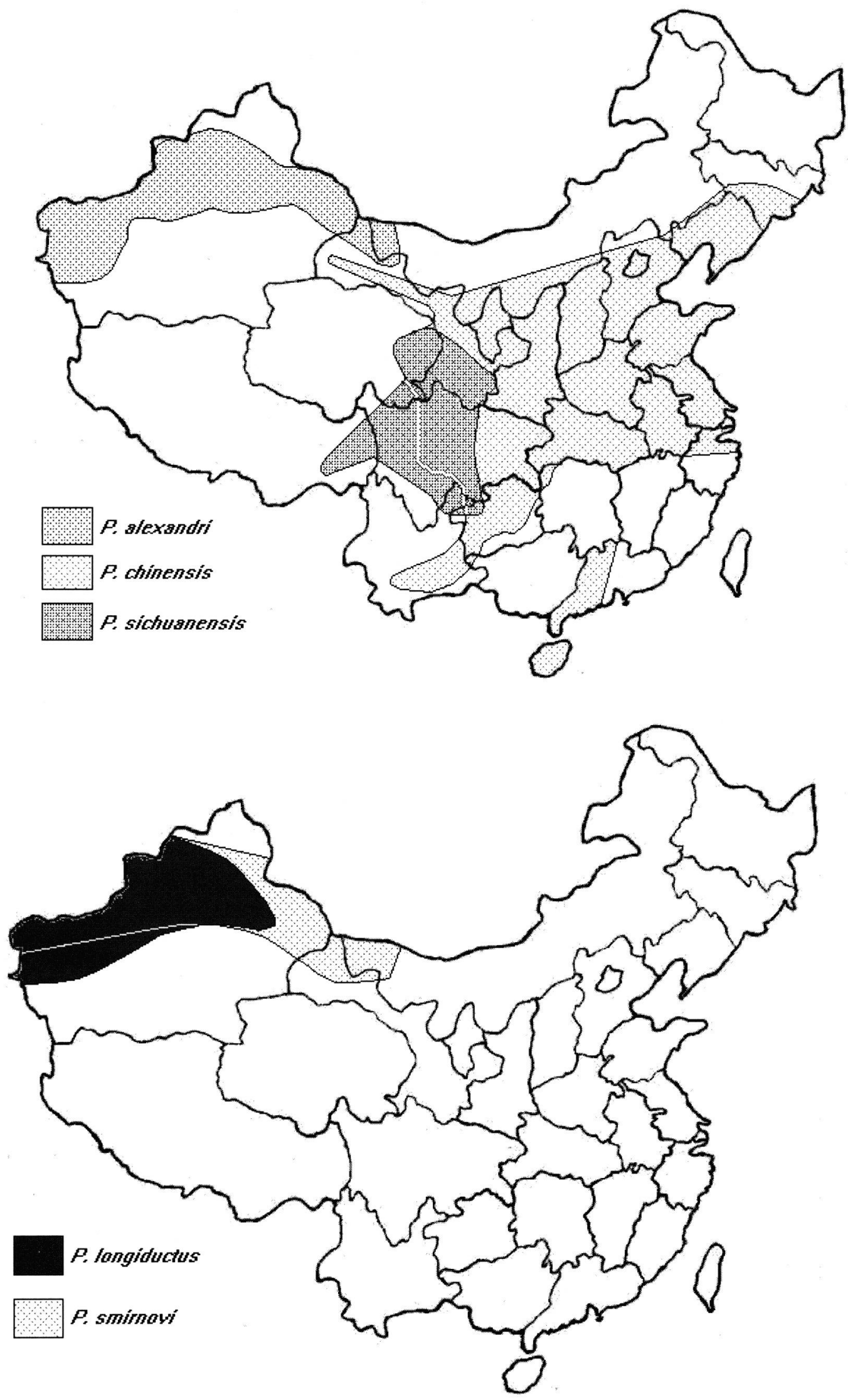

Fig. 1. - Diagrammatic distribution of phlebotomine vectors of VL in China. 


\begin{tabular}{|c|c|c|c|c|c|c|c|c|c|c|c|c|}
\hline \multirow[b]{2}{*}{ Species* } & \multicolumn{7}{|c|}{ Male } & \multicolumn{5}{|c|}{ Female } \\
\hline & Wing & A3 & A4 & $\mathrm{AF}$ & $\mathrm{HC}$ & GF & $\mathrm{F} / \mathrm{P}$ & Wing & A3 & $\mathrm{A} 4$ & $\mathrm{CDS}$ & SS \\
\hline P. ch & 2,104 & 419 & 34 & $2 / 3-15$ & 24 & 679 & 5.9 & 2,320 & 325 & 51 & + & $13-14$ \\
\hline P. si & 3,180 & 550 & 257 & $2 / 3-8,1 / 9-15$ & 39 & 1,130 & 7.1 & 2,750 & 370 & 148 & - & $15-18$ \\
\hline
\end{tabular}

* See table I. A3: antenna 3; A4: antenna 4; AF: ascoid formula; CDS: commonduct of spermatheca; GF: genital filament; F/P: genital filament/genital pump; HC: hairs on inner surface of coxite; SS: segments of spermatheca.

Table III. - Some morphological characters of P. chinensis and P. sichuanensis.

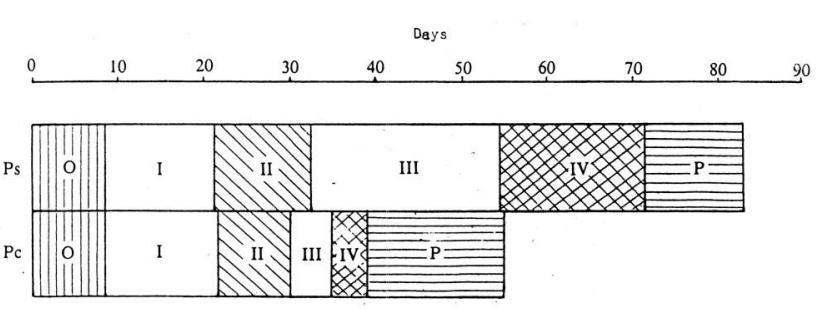

Fig. 2. - Developmental comparison of P. sichuanensis and P. chinensis (from Leng \& Zhang, 1992).

Pc: P. chinensis; Ps: P. sichuanensis; O: oval stage; I: first larval stage; II: second larval stage; III: third larval stage; IV: fourth larval stage; P : pupal stage.

- Morphological Characters (Leng \& Yin, 1983) ((Table III)

- Development (Fig. 2)

The time from oviposition to emergence of $P$. sichuanensis (83 days) is much longer than that of P. chi- nensis (55 days). Especially the third larval stage is much longer in $P$. sichuanensis (22 days) than that of P. chinensis ( 5 days) (Zhang, 1990).

- Characteristics at molecular level (Zhang \& Leng, 1991)

The allozyme phenotypes at different loci of phosphoglucomutase (PGM) and malate dehydrogenase (MDH-2) showed differences between P. sichuanensis from Sichuan and $P$. chinensis from Sichuan and Beijing. The MDH2 revealed a relative moving distance (RMD) 80 of alleles in P. chinensis from Beijing, but absent from Sichuan; and RMD 84 of alleles in $P$. sichuanensis. The PGM locus for genotype AA was over $77 \%$ in P. chinensis and $8.3 \%$ in P. sichuanensis; for genotype DD they were negative and $75 \%$ respectively (Fig. 3).

The molecular message showed evidences that $P$. sichuanensis and P. chinensis are two closely related but different species.
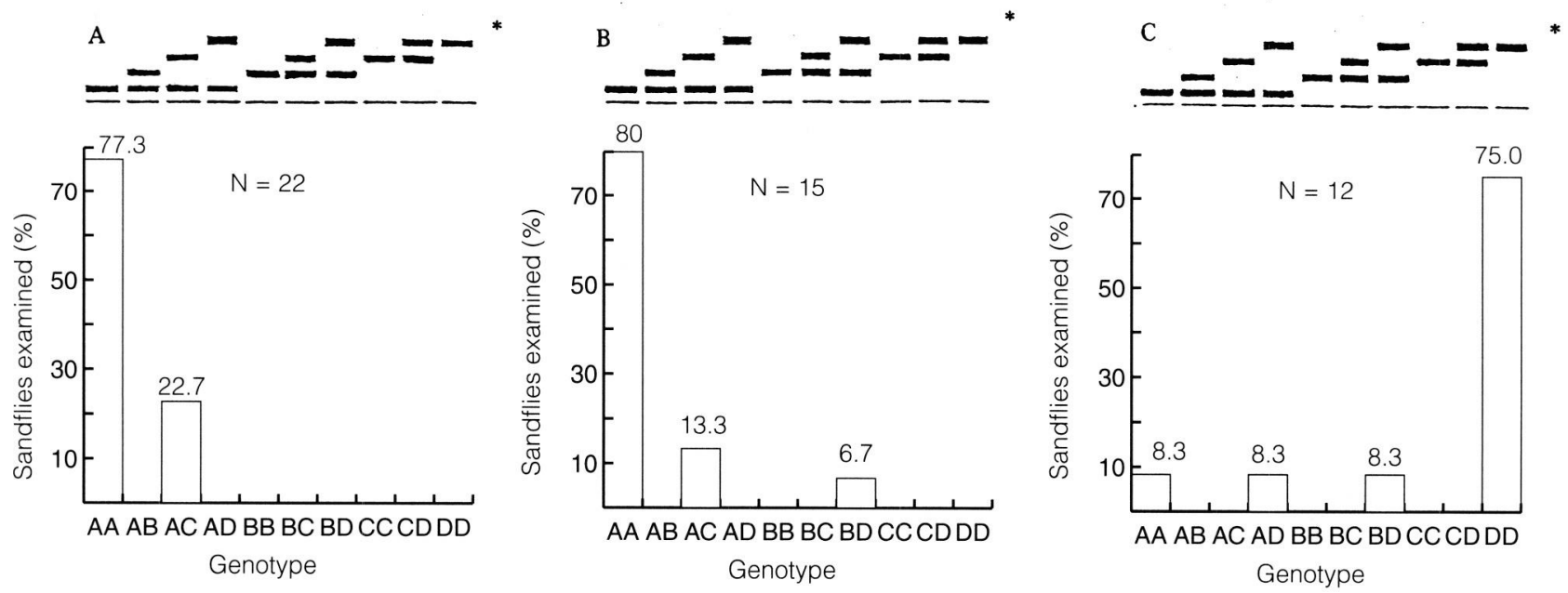

* Diagrammatic from of PGM electrophoretic bands

Fig. 3. - A comparison of the phosphoglucomutase enzyme genotype of $P$. chinensis and $P$. sichuanensis from Beijing and Sichuan (from Zhang \& Leng, 1991).

A: P. chinensis from Beijing; B: P. chinensis from Sichuan; C : P. sichuanensis from Sichuan. 


\begin{tabular}{|c|c|c|c|c|c|c|c|c|}
\hline & \multicolumn{5}{|c|}{ P. smirnovi } & \multicolumn{2}{|c|}{ "P. wui » } & \multirow[b]{2}{*}{ Remarks } \\
\hline & $\begin{array}{l}\text { Perfiliew } \\
\text { (1941) }\end{array}$ & $\begin{array}{c}\text { Perfiliew } \\
\text { (1948) }\end{array}$ & $\begin{array}{l}\text { A. \& N. } \\
(1984)\end{array}$ & $\begin{array}{l}\text { L. L. \& L. } \\
\text { (1987) }\end{array}$ & $\begin{array}{l}\text { Leng } \\
\text { (1991) }\end{array}$ & $\begin{array}{l}\text { Y. \& X. } \\
(1965)\end{array}$ & $\begin{array}{l}\text { A. \& N. } \\
(1984)\end{array}$ & \\
\hline \multicolumn{9}{|l|}{ Male } \\
\hline Aedeagus & $0.096-0.115$ & 0.12 & $\begin{array}{c}0.143 \\
(0.120-0.160)\end{array}$ & $\begin{array}{c}0.15 \\
(0.12-0.16)\end{array}$ & $\begin{array}{c}0.147 \\
(0.130-0.160)\end{array}$ & - & $\begin{array}{c}0.138 \\
(0.128-0.144)\end{array}$ & No difference \\
\hline Coxite & $0.27-0.29$ & $0.27-0.35$ & $\begin{array}{c}0.301 \\
(0.284-0.320)\end{array}$ & $0.31-0.37$ & $\begin{array}{c}0.300 \\
(0.272-0.314)\end{array}$ & 0.30 & $\begin{array}{c}0.291 \\
(0.264-0.316)\end{array}$ & No difference \\
\hline $\mathrm{H} / \mathrm{C}$ & $23+$ & $18+$ & $28(25-36)$ & $20-25$ & $26(21-29)$ & - & $25(15-23)$ & Overlapping \\
\hline Farmost hair & - & - & $0.55(0.51-0.57)$ & - & $0.52(0.41-0.61)$ & - & $0.54(0.51-0.57)$ & No difference \\
\hline Style & $0.14-0.15$ & $0.15-0.18$ & $\begin{array}{c}0.166 \\
(0.152-0.180)\end{array}$ & $\begin{array}{c}0.17 \\
(0.16-0.18)\end{array}$ & $\begin{array}{c}0.163 \\
(0.154-0.178)\end{array}$ & 0.15 & $\begin{array}{c}0.148 \\
(0.134-0.160)\end{array}$ & No difference \\
\hline $\mathrm{C} / \mathrm{S}$ & $1.92-1.93$ & $1.80-1.94$ & $1.67-1.95$ & $1.94-2.05$ & $1.63-2.01$ & 2 & $1.85-2.03$ & No difference \\
\hline GF/GP & - & 3 & 3.27 & 3 & 3.56 & - & 3 & No difference \\
\hline A. F. & $2 / 3-7,1 / 8-15$ & same & same & same & same & same & same & Identical \\
\hline Asc $4 / A 4$ & - & $1 / 5$ & 0.21 & $1 / 5$ & 0.23 & - & 0.25 & No difference \\
\hline W. L. & 1.90 & $1.92-2.16$ & $\begin{array}{c}1.81 \\
(1.64-2.14)\end{array}$ & $\begin{array}{c}1.93 \\
(1.83-2.10)\end{array}$ & $\begin{array}{c}1.73 \\
(1.62-1.84)\end{array}$ & 1.83 & $\begin{array}{c}1.66 \\
(1.52-1.80)\end{array}$ & Overlapping \\
\hline \multicolumn{9}{|l|}{ Female } \\
\hline A3 & - & $0.23-0.28$ & $\begin{array}{c}0.231 \\
(0.200-0.248)\end{array}$ & $\begin{array}{c}0.227 \\
(0.225-0.230)\end{array}$ & $\begin{array}{c}0.223 \\
(0.206-0.238)\end{array}$ & 0.21 & $\begin{array}{c}0.236 \\
(0.208-0.260)\end{array}$ & No difference \\
\hline $\mathrm{A} 3 / \mathrm{L}$ & - & $0.88-0.96$ & $\begin{array}{c}0.86 \\
(0.81-0.94)\end{array}$ & $\begin{array}{c}0.82 \\
(0.77-0.87)\end{array}$ & $\begin{array}{c}0.91 \\
(0.79-0.99)\end{array}$ & - & $\begin{array}{c}0.93 \\
(0.87-1.07)\end{array}$ & Overlapping \\
\hline Asc $4 / \mathrm{A} 4$ & - & - & $\begin{array}{c}0.31 \\
(0.28-0.35)\end{array}$ & $>1 / 5$ & $\begin{array}{c}0.32 \\
(0.22-0.42)\end{array}$ & - & $\begin{array}{c}0.35 \\
(0.30-0.40)\end{array}$ & Overlapping \\
\hline P. B. & - & - & $\begin{array}{c}0.056 \\
(0.048-0.064)\end{array}$ & $\begin{array}{c}0.063 \\
(0.055-0.070)\end{array}$ & $\begin{array}{c}0.065 \\
(0.058-0.070)\end{array}$ & 0.058 & $\begin{array}{c}0.060 \\
(0.052-0.064)\end{array}$ & Overlapping \\
\hline S. S. & 15 & $14-15$ & $16(14-18)$ & $12-16$ & $15(14-17)$ & $\begin{array}{c}14-16 \\
(12-19)\end{array}$ & $16(14-19)$ & Overlapping \\
\hline W. L. & 2.28 & 2.28 & $\begin{array}{c}2.05 \\
(1.96-2.16)\end{array}$ & 2.08 & $\begin{array}{c}1.95 \triangle \\
(1.80-2.08)\end{array}$ & 2.24 & $\begin{array}{c}2.12 \\
(1.98-2.46)\end{array}$ & Overlapping \\
\hline Locality & USSR & USSR & USSR & $\begin{array}{l}\text { USSR \& China } \\
\text { (Inner Mongolia) }\end{array}$ & China & China & Outer Mongolia & \\
\hline
\end{tabular}

A3: antenna 3; A3/L: antenna 3/labrum; A. F.: antennal formula; A. \& N.: Artemiev \& Neronov; Asc4/A4: ascoid (antenna 4) length/antenna 4 length; C/S: coxite/style; GF/GP: genital filament/genital pump; H/C: hairs/coxite; L. L. \& L.: Leng, Lane \& Lewis; P. B.: pharynx breadth; S. S.: spermatheca segments; Y. \& X.: Yang \& Xiong; $\triangle$ : measured from the alulet; $\square$ : Artemiev \& Neronov (1984) stressed main differential points.

Table IV. - Comparison of Phlebotomus (Larroussius) smirnovi from USSR, China and Mongolia.

- Different geographical distribution (Fig. 1)

$P$. chinensis is distributed up to $44^{\circ} \mathrm{N}$ in Jilin and Changchun, Jilin Province and southwards down to Danxian County, Hainan Island around $19.5^{\circ} \mathrm{N}$; in the east from the sea coast westward to a zigzag line running north to south along the eastern parts of Inner Mongolia, Shaanxi, Gansu, Qinghai, northern Sichuan, Guizhou, Guangxi and Hainan Island.

$P$. sichuanensis is distributed mainly in the southwestern mountainous areas of China. There is only a very small area of vertical and horizontal overlapping in geographical distribution between the two species.

\section{2/ P. smirnovi and P. wui}

(Leng, Lane \& Lewis, 1987; Leng, 1988a)
Ting \& Ho (1962) reported a new species named as $P$. major collected from Xinjiang Uyghur Autonomous Region. Yang \& Xiong (1965) described a new subspecies of Larroussius, $P$. major wui and concluded that Ting \& Ho's P. major was P. major wui. Artemiev \& Neronov (1984), Xiong \& Jing (1987) treated this subspecies as P. wui.

Leng et al. (1987) compared the paratype of Ting $\&$ Ho's P. major and Yang \& Xiong's P. major wui with $P$. smirnovi (included syntype and paratype) from proUSSR, and considered that $P$.wui is really a synonym of P. smirnovi.

- Morphological Characters (Table IV) have not obvious proper differences from the species mentioned above 
- Geographical distribution (Fig. 4) is in continuation from Central Asia to the northwest of China

- Ecological similarity (Table V)

Phlebotomine season of these "species " is similar.

- Evolutionary difference

Artemiev \& Neronov (1984) suggested that, during the historical migration, P. smirnovi spread eastward from Central Asia to the East of Junggar and Tarim Basins and evolved to a new species $P$. wui in these two basins. In fact, the first discovery and main distribution of $P$. major wui/P. wui are the west of Junggar and Tarim Basins. It is difficult to imagine that Artemiev \& Neronov's suggestion is true.

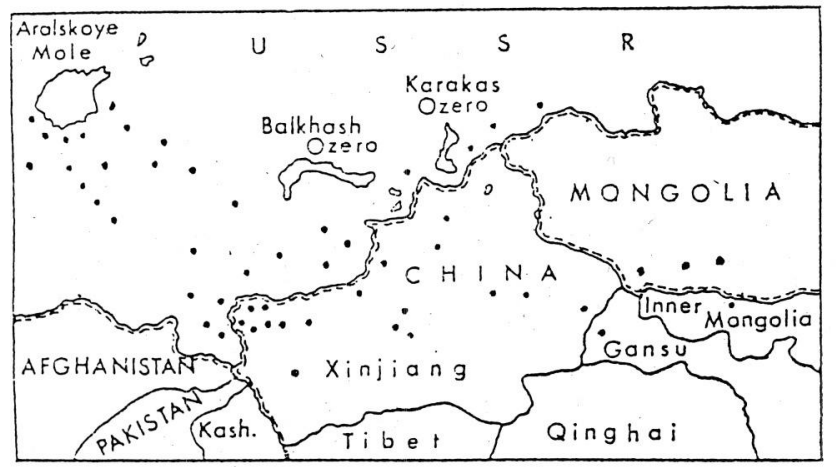

Fig. 4. - Zoogeographical distribution of Phlebotomus smirnovi (from Leng, 1988 b).

\section{THE VECTORS OF ANIMAL LEISHMANIA}

\section{WILD MAMMALS}

he natural infection by leishmanial parasites is quite common in great gerbil, Rhombomys optimus, in the desert area in north Xinjiang Uygur Autonomous Region and Ejin Banner, Inner Mongolia Autonomous Region (Guan et al., 1982, 1994b). These parasites can cause ear-lesion in great gerbil. Two species of Leishmania, L. turanica and L. gerbilli have been found in great gerbil's ear lesion. The main vectors of these two leishmanial parasites are $P$. mongolensis and P. andrejievi in Ejin Banner, Inner Mongolia Autonomous Region (Guan et al., 1982); P. smirnovi, P. andrejievi, P. mongolensis and P. caucasicus in Xinjiang Uygur Autonomous Region (Xiong et al., 1964; Guan et al., 1994b) and P. alexandri, P. mongolensis in Gansu Province (Wang et al., 1964). In gerbil burrows, these sandflies are predominant and their natural infection rates by Leishmania are shown in table VI. Infected case of P. smirnovi with gerbil Leishmania is different in some places. It is considered being the main vector in Karamay, Xinjiang, but the possibility to be vectors in Ejin Banner, Inner Mongolia and Gansu is very little (Guan et al., 1982, 1986a, 1994a; Liu et al., 1982; Xiong et al., 1964). Other experiments suggest that $P$. alexandri might be a favourable host for $L$. gerbilli (experimental infection rate is about $67.6 \%$, Guan et al., 1986a) (Table VII). Other facts have shown that after inoculating the Leishmania isolated from Karamay big gerbils, a monkey showed an ulceration of dermis and one of two human volunteers developed cutaneous leishmaniasis. Leishmania parasites were found in macrophages of the dermis and in the epithelial cells of hair follicles. This indicates that Leishmania parasite of the Karamay great gerbils is pathogenic to monkey and man, and that great gerbil is a potential reservoir of human cutaneous leishmaniasis in this area (Guan et al., 1992).

\section{WILD LIZARD}

The natural infection of Leishmania in lizards is found in the Ejin Banner, Inner Mongolia Autonomous Region. The main vector of lizards leishmania is considered to be $S$. (S.) sinkiangensis with a natural infected rate of $13.0 \%$ and promastigotes filled up fore-, mid-, hind- gut (Guan et al., 1982) (Table VI). This sandfly prefers the blood of lizard and is tightly associated with the lizard in nature (Guan et al., 1991).

\begin{tabular}{|c|c|c|c|c|c|c|c|}
\hline \multirow[b]{2}{*}{ Species } & \multirow[b]{2}{*}{ Distribution } & \multicolumn{5}{|c|}{ Season } & \multirow[b]{2}{*}{ Reference } \\
\hline & & Start & Pea & & End & Period & \\
\hline P. wui & $\begin{array}{c}\text { Xinjiang } \\
\text { Inner Mongolia }\end{array}$ & $\begin{array}{l}\text { E/May } \\
\text { E/June }\end{array}$ & $\begin{array}{l}\text { (1) } \mathrm{M} / \text { June (2) } \\
\mathrm{L} / \text { June to }\end{array}$ & $\begin{array}{l}\text { M/August } \\
\text { E/July }\end{array}$ & $\begin{array}{l}\text { L/September } \\
\text { L/August }\end{array}$ & $\begin{array}{c}4.5-5 \mathrm{~m} \\
3 \mathrm{~m}\end{array}$ & $\begin{array}{l}\text { Xiong, } 1979 \\
\text { Xiong, } 1976,1979\end{array}$ \\
\hline P. smirnovi & Central Asia & M/May & (1) $\mathrm{L} /$ June (2) & L/July & L/September & $4.5-5 \mathrm{~m}$ & Artemiev, 1984 \\
\hline
\end{tabular}

Table V. - Ecology of P. smirnovi and P. wui. 


\section{Distribution of promastigotes in sandflies}

\begin{tabular}{|c|c|c|c|c|c|c|c|c|c|}
\hline Species* & Infected rate $(\%)$ & Proboscis & Buccal cavity & Pharynx & Esophagus & Pro-gut & Mid-gut & Hind-gut & Reference \\
\hline P. an & 12.8 & - & - & - & 8.3 & 41.7 & 100.0 & 8.3 & Guan, 1982 \\
\hline P. an & 13.0 & 6.3 & - & 0 & 12.5 & 18.8 & 100.0 & 25.0 & Guan, $1994 b$ \\
\hline P. al & 4.6 & 11.1 & - & 77.8 & 88.9 & 88.9 & 100.0 & 11.1 & Wang, 1964 \\
\hline P. ca & 22.8 & - & - & 9.5 & 19.0 & 52.4 & 95.2 & 28.6 & Xiong, 1964 \\
\hline P. mo & 0.8 & - & - & + & + & ++ & + & ++ & Wang, 1964 \\
\hline P. mo & 17.2 & 0.7 & - & 9.3 & 17.9 & 43.0 & 100.0 & 8.6 & Xiong, 1964 \\
\hline P. mo & 10.0 & 2.9 & - & - & 11.4 & 54.3 & 94.3 & 17.1 & Guan, 1982 \\
\hline P. mo & 8.1 & 0 & - & 0 & 13.3 & 33.3 & 100.0 & 0 & Guan, $1994 b$ \\
\hline S. si & 1.6 & + & - & + & + & + & + & + & Xiong, 1965 \\
\hline S. si & 13.0 & 0 & - & 10.0 & 30.0 & 60.0 & 100.0 & 40.0 & Guan, 1982 \\
\hline P. sm & 13.0 & 23.8 & - & 38.1 & 66.6 & 85.7 & 100.0 & 23.8 & Xiong, 1964 \\
\hline S. sm & 1.1 & - & - & - & - & 33.3 & 100.0 & 33.3 & Guan, 1982 \\
\hline
\end{tabular}

${ }^{*}$ P. an: P. andrejievi; P. ca: P. caucasicus; P. mo: P. mongolensis; S. si: S. sinkiangensis.

Table VI. - Natural infection of several species of sandfly with animal Leishmania.

Distribution of promastigotes in sandflies

\begin{tabular}{|c|c|c|c|c|c|c|c|c|c|}
\hline Species* & Infected rate $(\%)$ & Proboscis & Buccal cavity & Pharynx & CEsophagus & Pro-gut & Mid-gut & Hind-gut & Reference \\
\hline P. al & 67.6 & 8.7 & - & 13.0 & 47.8 & 91.3 & 100.0 & 8.7 & Guan, $1986 a$ \\
\hline P. mo & 33.3 & 0 & - & 0 & 15.0 & 45.0 & 100.0 & 0 & Xiong, 1964 \\
\hline P. lo & 32.8 & 0 & - & 10.5 & 73.7 & 100.0 & 100.0 & 10.5 & Guan, $1986 a$ \\
\hline S. si & 16.2 & - & - & - & + & + & + & + & Xiong, 1965 \\
\hline P. sm & 20.6 & 0 & 0 & 0 & 0 & 71.4 & 100.0 & 14.3 & Guan, $1986 a$ \\
\hline
\end{tabular}

* See table I and table VI.

Table VII. - Artificial infection of sandflies with animal Leishmania.

\section{REFERENCES}

Artemiev M.M. \& Neronov V.M. Distribution and ecology of sandflies of the Old World (genus Phlebotomus). In: The USSR Committee for the UNESCO Programme on Man and the Biosphere (MAB), 1984, pp. 70-71, 103-105, Institute of Evolutionary Morphology and Animal Ecology, USSR Academy of Sciences, Moscow (in Russian).

GuAn L.R. et al. Studies on Leishmania in big gerbils and lizards and its sandfly vectors in Ejin Banner, Inner Mongolia Autonomous Region. Acta Academiae Medicinae Sinicae, 1982, 4 (5), 261-265 (in Chinese).

GuAN L.R. et al. Experimental infection of three subgenus of Phlebotomus with Leishmania gerbilli. Endemic Diseases Bulletin, 1986a, 1 (1), 73-76 (in Chinese).

Guan L.R. et al., The role of Phlebotomus alexandri Sinton, 1928 in the transmission of kala-azar. Bulletin of the World Health Organization, 1986b, 64 (1), 107-112.

GuAn L.R. et al. Leishmaniasis in Karamay V. Observation on the bionomics of sandflies in Karamay, Xinjiang, China. Endemic Diseases Bulletin, 1991, 6 (2), 55-61 (in Chinese).

GuAn L.R. et al. Leishmaniasis in Karamay XI. The development of cutaneous leishmaniasis in monkey and man experimentally infected with Leishmania from Karamay big gerbil. Chinese Journal of Parasitology and Parasitic Diseases, 1992, 10 (4), 263-266 (in Chinese with English summary).

GUAN L.R. et al. Leishmaniasis in Karamay XIV. Identification of promastigote isolates from naturally infected Phlebotomus major wui. Chinese Journal of Parasitology and Parasitic Diseases, 1994a, 12 (4), 257-261 (in Chinese with English summary).

GUAN L.R. et al. Studies on the living environment of great gerbil and its natural infection of Leishmania and sandfly vectors in North Xinjiang, China. Endemic Diseases Bulletin, 1994b, 9 (4), 7-10 (in Chinese).

LENG Y.J. A review of phlebotomine sandflies and their transmission of leishmaniasis in China. Jpn. J. Sanit Zool., $1988 a, 39$ (4), 323-337.

LENG Y.J. A review of leishmaniasis research in China from 1960 to 1986. Jpn. J. Parasitol., 1988b, 37 (3), 119-132.

LENG Y.J. Personal communication, 1991 (in Chinese).

LENG Y.J. \& Yin Z.C. The taxonomy of phlebotomine sandflies (Diptera: Psychodiae) of Sichuan Province, China, with descriptions of two species, Phlebotomus (Adlerius) sichuanensis sp. n. and Sergentomyia (Neophlebotomus) 
zhengjiani sp. n. Annals of Tropical Medicine and Parasitology, 1983, 77, 421-432.

Leng Y.J. \& Zhang L.M. Phlebotomus (Adlerius) sichuanensis: a potential vector of visceral leishmaniasis in southwestern mountainous areas of China. Chinese Journal of Parasitology, 1992, 5, 73-80.

Leng Y.J. \& Zhang L.M. Check list and geographical distribution of phlebotomine sandflies in China. Annals of Tropical Medicine and Parasitology, 1993, 87, 83-94.

LENG Y.J., Lane R.P. \& Lewis D.J. The identity of two species of phlebomine sandflies from Xinjiang, China. Annual Bulletin of the Society of Parasitology, Guangdong Province, 1987, 8-9, 40-43 (in Chinese).

LIU P.Z. et al. Gerbillis leishmaniasis in the desert of West of Yellow River, Gansu Province. Chinese Journal of Epidemiology, 1982, 3 (5), 304-305 (in Chinese).

Ting S.T. \& Ho K.T. Notes on the Chinesis species of genus Phlebotomus. Part IX. Sandflies in Sinkiang Urghur Autonomous Region with description of Phlebotomus minutus var. sinkiangensis n. var. Acta Entomol. Sinica, 1962, 11 (4), 388-393 (in Chinese with English summary).

WANG C.S. et al. Advances in investigations and studies on kala-azar in China since 1960. J. Parasit. Parasitic Diseases, 1983, 1 (2), 65-73 (in Chinese).

WANG J. et al. The Leishmania infection found in Rhombomys opimus its transmission and relation to man. Acta Parasitologica Sinica, 1964, 1 (1), 17-23 (in Chinese with English summary).

XIONG G.H. \& Jin C.F. On the classification of subgenus Larroussius Nitzulesu, 1931 and Phlebotomus wui stat. nov. (Diptera: Psychodidae). Chin.J. Parasitol. Dis., 1987, 5, 4547 (in Chinese with English summary).

Xiong G.H. (Hisung K.H.) et al. Experimental infection of $P$. alexandri and P. mongolensis with Leishmania donovani. Acta Zoologica Sinica, 1963, 15 (4), 607- 610 (in Chinese with English summary).

XIONG G.H. et al. Studies on gerbil leishmaniasis in Sinkiang: its sandfly vectors and relation to man. Acta Parasitologica Sinica, 1964, 1 (2), 130-136 (in Chinese with English summary).

XIOng G.H. et al. The relation of Phlebotomus minutus sinkiangensis Ting \& Ho 1962 to leishmania infection in Sinkiang China. Acta Parasitologica Sinica, 1965, 2 (1), 1822 (in Chinese with English summary).

XIOng G.H. et al. Study on vectors of kala-azar transmission in Xinjiang. Joumal of Control and Research of Epidemic Diseases, 1974, 4, 327-334 (in Chinese).

XIOng G.H. et al. The natural nidus of Kala-azar in Northwest China. Res. Control Epi. Dis, 1976, (1), 63-68 (in Chinese).

Xiong G.H. (Hsiung Kunang Hua) et al. The bionomics of P. major wui Yang \& Hsiung, 1965, and its control in desert area of Sinkiang. Acta Entomologica Sinica, 1979, 22 (4), 428-436 (in Chinese with English summary).

XIong G.H. et al. Studies on longitudinal distribution of $P$. chinensis and its relation to kala-azar in Southern Gansu and Northern Sichuan. Institute of Parasitic Diseases
Chinese Academy of Preventive Medicine 1988 Annual Report, 1988, 99-103 (in Chinese).

XIOng G.H. et al. Studies on the bionomics of sandfly, P. chinensis Newstead, 1916, and relation to the visceral leishmaniasis in Southern Gansu and Northern Sichuan, China. Wuyi Science Journal, 1992, 9, 7-17 (in Chinese).

YANG K.Y. \& XiOng G.H. A new species of sandfly Pblebotomus major wui subsp. nov. from Sinkiang, China. Acta Parasitol. Sin., 1965, 2, 412-415 (in Chinese with English summary).

YIN Z.C. Survey of kala-azar epidemiology in sichuan Province. Research and Prophylaxis of Parasitic Diseases, 1985 (3), 24-34 (in Chinese).

ZHANG L.M. Laboratory cultivation of Phlebotomus sichuanensis (Diptera: Paychodidae). Acta Entomologica Sinica, 1990, 33 (3), 380-381 (in Chinese).

ZHANG L.M. \& LENG Y.J. A preliminary isoenzyme study of five species of phlebotomine sandflies in China. Parassitologia, 1991, 33 (Suppl. 1), 541-550. 